\title{
HARMONISA LISTRIK GEDUNG PUSDIKLAT KETENAGALISTRIKAN ENERGI BARU TERBARUKAN DAN KONSERVASI ENERGI (KEBTKE) CIRACAS (SUATU STUDI PENELITIAN DI GEDUNG UTAMA PUSDIKLAT CIRACAS)
}

\author{
${ }^{1}$ Ady Wartono, ${ }^{2}$ Irzan Zakir, ${ }^{3}$ Massus Subekti \\ 1,2,3 Pendidikan Teknik Elekto, Fakultas Teknik - Universitas Negeri Jakarta \\ ${ }^{1}$ E-mail:Ady.Wartono@gmail.com
}

\begin{abstract}
Harmonic distortion is a phenomenon arising due to the use of a non linear load on the power system. This phenomenon can cause problems on quality in terms of power will eventually cause various losses and even damage to several electrical appliances. The purpose of this research is to know the value of the harmonic distortion of current/Total Harmonic Distortion (THDi) and voltage/Total Harmonic Distortion (THDv) of electrical installation system Pusdiklat (KEBTKE) Ciracas using by Power Quality Analyzer and load mappings for each floor.

This research was carried out at the main building of Pusdiklat KEBTKE on Jl. Poncol Raya No. 39, Ciracas, East Jakarta. Time research was done at 12:15 pm to 7:15 pm, from June 11 until June 15, 2016. The methods used in this research is descriptive analysis methods with quantitative approach, namely the research results which are then processed and analyzed to be taken to summarize.

The content of the current harmonic distortion (THDi) on building Pusdiklat KEBTKE in general is above the permitted standard. Measurement data at 12:15 am-7:15 pm who performed on June 10 to June 14, total harmonics distortion (THDI\%) exceeded 15\% except at certain times at the moment at least the use of other electronic or computers equipment in each floor of the building. The content of the current harmonic distortion (THDI) generally do not experience interference voltage harmonization. Based on measurement data at 12:15 am-7:15 pm who performed on June 10 to June 14 , total harmonic distortion of voltage distortion (THDV) does not exceed $5 \%$.
\end{abstract}

Keywords: electrical Harmonics, voltage, current, Load the Non Linear

\begin{abstract}
Abstrak
Harmonisa merupakan suatu fenomena yang timbul akibat adanya penggunaan beban non linier pada sistem tenaga listrik. Fenomena ini dapat menimbulkan masalah pada segi kualitas daya yang akhirnya akan menyebabkan berbagai kerugian dan bahkan kerusakan pada bebarapa peralatan listrik. Tujuan dari penelitian ini adalah untuk mengetahui nilai harmonisa arus/Total Harmonic Distortion (THDI) dan tegangan/Total Harmonic Distortion (THDV) sistem instalasi listrik ketenagalistrikan energi baru terbarukan dan konservasi energi (KEBTKE).

Penelitian ini dilaksanakan pada gedung utama Pusdiklat ketenagalistrikan energi baru terbarukan dan konservasi energi (KEBTKE) Jl.Poncol Raya No.39,Ciracas, Jakarta Timur. Waktu penelitian dilakukan pada pukul 12:15 WIB hingga 19:15 WIB, dari tanggal 11 Juni sampai 15 Juni 2016. Metode yang digunakan dalam penelitian ini adalah metode deskriptif analisis dengan pendekatan kuantitatif.

Kandungan harmonisa arus (THDI) pada gedung Pusdiklat ketenagalistrikan energi baru terbarukan dan konservasi energi (KEBTKE) secara umum berada di atas standar yang diiziinkan. Data pengukuran pukul 12:15 WIB - 19:15 WIB yang dilakukan pada tanggal 10 Juni 2016 hingga 14 Juni 2016 distorsi total harmonisa (\%THDI) melebihi batas 15\% Kecuali pada waktu- waktu tertentu pada saat sedikitnya penggunaan komputer atau peralatan elektronik lain di tiap lantai gedung tersebut. Kandungan harmonisa arus (THDI) secara umum tidak mengalami gangguan harmonisasi tegangan listrik. Berdasarkan data pengukuran pukul 12:15 WIB - 19:15 WIB yang dilakukan pada tanggal 10 Juni 2016 hingga 14 Juni 2016 distorsi total harmonisa tegangan (THDV) tidak melebihi batas 5\% .
\end{abstract}

Kata Kunci: harmonisa listrik, tegangan, arus, beban non linier

\section{PENDAHULUAN}

Energi listrik merupakan salah satu unsur penting dalam kehidupan manusia. Tidak dapat dipungkiri lagi, saat ini listrik menjadi salah satu kebutuhan yang sifatnya pokok. Hal ini disebabkan karena hampir semua kegiatan manusia berhubungan dengan pemakaian energi listrik. Seperti yang telah kita ketahui bersama, energi listrik digunakan baik itu untuk keperluan pribadirumah tangga, perusahaan, industri dan sebagainya.

Seiring dengan berkembangnya kemajuan alat-alat kelistrikan maka semakin banyak pula peralatan listrik yang termasuk ke dalam jenis beban-beban non linier. Beban non linier banyak digunakan karena praktis dan mudah dalam hal pengontrolannya. Di sisi lain, beban non linier yang pada umumnya terbuat dari bahan-bahan semikonduktor dan elemen elektronika daya dapat menimbulkan harmonisa pada sistem tenaga listrik.

Harmonisa merupakan suatu fenomena yang timbul akibat adanya penggunaan beban non linier pada sistem tenaga listrik. Fenomena ini dapat menimbulkan masalah pada segi kualitas daya yang akhirnya akan menyebabkan berbagai 
kerugian dan bahkan kerusakan pada bebarapa peralatan listrik. Harmonisa menjadi suatu hal yang sangat penting untuk dipelajari dan dikaji karena jika tidak segera ditangani, maka dampak buruk yang ditimbulkannya akan semakin besar dan berpengaruh buruk terhadap kinerja peralatan kelistrikan.

Pusdiklat ketenagalistrikan energi baru terbarukan dan konservasi energi (KEBTKE) memanfaatkan gedung bertingkat sebagai kantor utama. Sistem tenaga listrik yang digunakan pada gedung Pusdiklat secara keseluruhan menggunakan sistem tegangan tiga fasa dengan arus bolak-balik.

Sistem distribusi listrik pada gedung Pusdiklat ketenagalistrikan energi baru terbarukan dan konservasi energi (KEBTKE) disalurkan melalui saluran dengan menggunakan tiga kawat utama sebagai fasa dan satu kawat sebagai netral. Sehingga jumlah daya yang disalurkan pada masing-masing fasa sama dengan daya tiga fasa yang disalurkan. Perencanaan awal suatu sistem instalasi listrik sangat mempengaruhi kehandalan energi listik yang disalurkan pada suatu gedung dan pemanaatan energi listrik secara efisien.

Arus sistem tenaga listrik yang terdistorsi tersebut umumnya didominasi oleh arus harmonisasi orde ganjil rekuensi rendah, yaitu arus harmonisasi orde lima, tujuh, sebelas, dan seterusnya yang magnitude arus harmonisanya berbanding terbalik dengan orde harmonisanya. Tingginya Presentae kandungan harmonisa arus (THD) pada suatu sistem tenaga listrik dapat menyebabkan timbulnya beberapa persoalan.

Harmonisa yang serius pada sistem tersebut dan lingkungannya, seperti terjadinya resonansi pada sistem yang merusak kapasitor kompensasi faktor daya, kerusakan pada peralatan listrik yang sensitif yang membuat penggunaan energi listrik menjadi tidak efektif. Sebagai lembaga pusat pelatihan Pusdiklat ketenagalistrikan energi baru terbarukan dan konservasi energi (KEBTKE) memberikan beberapa bentuk layanan yang diberikan untuk menunjang kemajuan pemanfaatan energi terbarukan.

Dalam menjalankan tugas dan tanggung jawab dengan baik maka gedung ketenagalistrikan energi baru terbarukan dan konservasi energi (KEBTKE) dilengkapi dengan infrastruktur seperti sistem jaringan antar komputer local area network (LAN) dan internet. Selain itu juga terdapat server utama komputer sebagai aplikasi komputer yang berjalan pada infrastruktur jaringan komputer.

Berdasarkan penjelaskan di atas, maka penelitian ini akan mencoba mempelajari dan menganalisa berapa besar Total Harmonic Distortion (THD) yang terjadi di gedung Pusdiklat ketenagalistrikan energi baru terbarukan dan konservasi energi (KEBTKE) Ciracas sebagai akibat banyaknya beban-beban listrik nonlinier menggunakan alat ukur Power Quality Analyzer dan observasi pemetaan beban non linier di tiap lantainya.

Sistem tenaga listrik dirancang untuk beroperasi pada frekuensi $50 \mathrm{~Hz}$ atau $60 \mathrm{~Hz}$. Akan tetapi dalam kenyataannya terdapat beberapa beban yang menyebabkan munculnya arus dan tegangan yang frekuensinya merupakan kelipatan 50 atau $60 \mathrm{~Hz}$. Beban tersebut dinamakan sebagai beban non linier. Sedangkan frekuensi 50 atau $60 \mathrm{~Hz}$ disebut sebagai frekuensi fundamental dan kelipatannya disebut harmonisa atau harmonik.

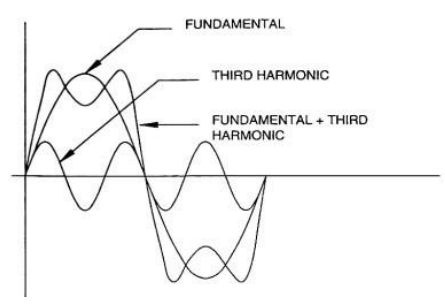

Gambar 1. Penjumlahan Gelombang Harmonisa

Harmonisa adalah distorsi periodik dari gelombang sinus arus, tegangan, atau daya dengan bentuk gelombang yang frekuensinya merupakan kelipatan selain bilangan satu terhadap frekuensi fundamental yang mana pada sistem suplai dirancang beroperasi pada $50 \mathrm{~Hz} / 60$ Hz (Sugiarto, 2012: 80).

Standar harmonisa berisi tentang panduan, rekomendasi praktis ataupun batasan harmonik agar sistem kelistrikan yang ada tidak mengalami hal-hal yang tidak diinginkan. Standar ini melibatkan semua pihak mulai dari sisi penyuplai sampai sisi konsumen untuk kesesuaian peralatan sisi beban dengan peralatan sistem, sehingga ketidaksesuaian respon akibat harmonik dapat diminimalisir. Dalam menentukan batasan 
harmonisa arus dan tegangan digunakan standar sebagai acuan. Tabel berikut memperlihatkan batasan harmonik arus dan tegangan listrik sesuai standar IEEE:

Tabel 1. Batasan Harmonik Arus Standar IEEE

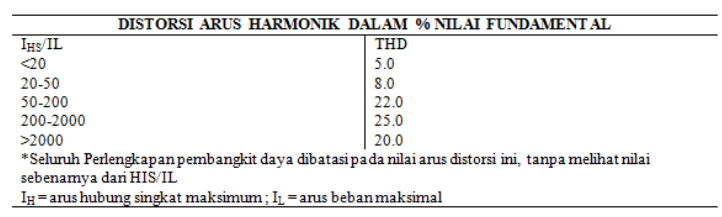

Tabel 2. Batasan Harmonik Tegangan Standar IEEE

\begin{tabular}{cccc}
\hline \multicolumn{4}{c}{ Distorsi Tegangan Harmonik Dalam \% Nilai Fundamental } \\
\hline Sistem Tenaga & $<69 \mathrm{kV}$ & $69-238 \mathrm{kV}$ & $>238 \mathrm{kV}$ \\
THD & 5,0 & 2,5 & 2,5 \\
\hline
\end{tabular}

Seiring dengan berkembangnya kemajuan alat-alat kelistrikan maka semakin banyak pula peralatan listrik yang termasuk ke dalam jenis beban-beban non linier. Beban non linier banyak digunakan karena praktis dan mudah dalam hal pengontrolannya. Di sisi lain, beban non linier yang pada umumnya terbuat dari bahan-bahan semikonduktor dan elemen elektronika daya dapat menimbulkan harmonisa pada sistem tenaga listrik.

Harmonisa merupakan suatu fenomena yang timbul akibat adanya penggunaan beban non linier pada sistem tenaga listrik.Fenomena ini dapat menimbulkan masalah pada segi kualitas daya yang akhirnya akan menyebabkan berbagai kerugian dan bahkan kerusakan pada bebarapa peralatan listrik. Harmonisa menjadi suatu hal yang sangat penting untuk dipelajari dan dikaji karena jika tidak segera ditangani, maka dampak buruk yang ditimbulkannya akan semakin besar dan berpengaruh buruk terhadap kinerja peralatan kelistrikan.

Berikut ini dikemukakan penelitian yang relevan dengan membahas permasalahan yang sesuai dengan penelitian ini yaitu : Irfan Kurniawan, Mahasiswa Teknik Elektro, Fakultas Teknik Universitas Indonesia, dengan judul "Analisis Pengaruh Harmonisa Terhadap Penyimpangan Pengukuran Energi Listrik pada KWH Meter Analog dan Digital", membahas secara luas tentang harmonisasi arus dan tegangan serta serta mengaitkan dengan pengaruh terhadap penyimpangan pengukuran energi listrik KWH meter (Skripsi, 2012:2).

Dalam penelitian ini peneliti akan mengkaji harmonisasi arus dan tegangan listrik di gedung
Pusdiklat ketenagalistrikan energi baru terbarukan dan konservasi energi (KEBTKE) Ciracas. Data yang digunakan dalam penelitian ini didapat dari hasil pengukuran menggunakan Power Quality Analyzer serta data pemetaan beban tiap latai gedung Pusdiklat. Pengolahan data hasil pemetaan beban dianalisia keterkaitannya pada tiap jenis hasil pengukuran yang terjadi pada saat pemanfaatan energi listrik gedung Pusdiklat ketenagalistrikan energi baru terbarukan dan konservasi energi KEBTKE Ciracas.

Tahapan dalam penelitian ini adalah peneliti melakukan evaluasi konfigurasi instalasi listrik gedung utama Pusdiklat ketenagalistrikan energi baru terbarukan dan konservasi energi KEBTKE Ciracas dari lantai dasar sampai lantai empat. Setelah mendapatkan data pengukuran peneliti akan melakukan analisa data hasil pengukuran untuk mengetahu besar harmonisasi arus dan tegangan listrik gedung tersebut.

\section{METODE}

Metode yang digunakan dalam penelitian ini adalah metode deskriptif analisis dengan pendekatan kuantitatif, yaitu hasil penelitian yang kemudian diolah dan dianalisis untuk diambil kesimpulannya, artinya penelitian yang dilakukan adalah penelitian yang menekankan analisisnya pada data-data numerik (angka) sehingga menghasilkan kesimpulan yang akan memperjelas gambaran mengenai objek yang diteliti.

Penelitian ini dilaksanakan pada gedung utama Pusdiklat KEBTKE Jl Poncol Raya No.39, Ciracas, Jakarta Timur. Waktu penelitian dilakukan pada pukul 12:15 WIB hingga 19:15 WIB, tanggal 11 Juni sampai 15 Juni 2016.

\section{HASIL DAN PEMBAHASAN}

Berdasarkan analisa data hasil pengukuran harmonisasi tegangan listrik gedung Pusdiklat ketenagalistrikan energi baru terbarukan dan konservasi energi (KEBTKE) tidak mengalami gangguan harmonisasi tegangan listrik . Berdasarkan data pengukuran pukul 12:15 WIB 19:15 WIB yang dilakukan pada tanggal 10 Juni 2016 hingga 14 Juni 2016 distorsi total 
harmonisa tegangan (THDV) tidak melebihi batas 5\% (Standar IEEE No.519-1992).

Hanya terjadi kenaikan atau transient tegangan namun tidak melebihi 5\%, Berdasarkan data pengukuran (THDV) di lantai pada tanggal 11 Juni 2016 pada fasa T dengan nilai (THDV) 2,49\% (pukul 19:15 WIB). Sedangkan untuk nilai (THDV) terendah terjadi pada tanggal 12 Juni 2016 pada fasa $\mathrm{S}$ dengan nilai (THDV) 1,45\% (pukul 13:15 WIB).

Berikut adalah grafik hasil pengukuran harmonisa tegangan pada gedung Pusdiklat ketenagalistrikan energi baru terbarukan dan konservasi energi (KEBTKE) Cirascas dengan menggunakan nilai rata-rata tiap fasa pada tanggal 11 Juni 2016 sampai 15 Juni 2016, pukul 12:15 WIB sampai 19:15 WIB.

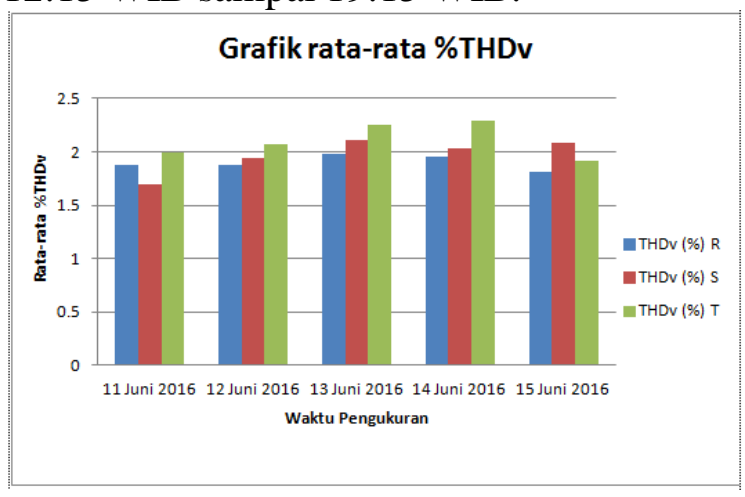

Gambar 2. Grafik rata-rata \%THDv

\section{KESIMPULAN DAN SARAN \\ Kesimpulan}

Dari hasil pengukuran yang telah dilakukan menggunakan Power Quality Analyzer maka dapat diambil kesimpulan, yaitu:

1. Kandungan harmonisa arus (THDI) pada gedung Pusdiklat ketenagalistrikan energi baru terbarukan dan konservasi energi (KEBTKE) secara umum berada di atas standar yang diiziinkan. Data pengukuran pukul 12:15 WIB - 19:15 WIB yang dilakukan pada tanggal 10 Juni 2016 hingga 14 Juni 2016 distorsi total harmonisa (\%THDI) melebihi batas $15 \%$ Kecuali pada waktu- waktu tertentu pada saat sedikitnya penggunaan komputer /peralatan elektronik lain di tiap lantai gedung tersebut.

2. Kandungan harmonisa arus (THDI) pada gedung Pusdiklat ketenagalistrikan energi baru terbarukan dan konservasi energi (KEBTKE) secara umum tidak mengalami gangguan harmonisasi tegangan listrik. Berdasarkan data pengukuran pukul 12:15 WIB - 19:15 WIB yang dilakukan pada tanggal 10 Juni 2016 hingga 14 Juni 2016 distorsi total harmonisa tegangan (THDV) tidak melebihi batas $5 \%$.

3. Berdasarkan hasil pengukuran di sisi suplai, diketahui bahwa arus netral yang mengalir pada jaringan listrik di gedung Pusdiklat ketenagalistrikan energi baru terbarukan dan konservasi energi (KEBTKE) pada waktu tertentu nilainya bisa mendekati arus fasa. Ini berarti rugirugi daya terjadi sangat besar.

4. Fluktuasi nilai tegangan di gedung Pusdiklat ketenagalistrikan energi baru terbarukan dan konservasi energi (KEBTKE) berada di kisaran 220,4V$229,5 \mathrm{~V}$. nilai tegangan ini masih sesuai standar yang telah ditentukan.

\section{Saran}

1. Melakukan evaluasi ulang untuk memaksimalkan pemanfaatan energi listrik yang disesuaikan dengan kebutuhan gedung.

2. Untuk dapat memperbaiki kualitas arus perlu dilakukan pengaturan kembali konfigurasi jaringan berupa pemecahan beban non-linier pada setiap lantai, dengan memperhatikan keseimbangan fasa untuk mengurangi (\%THDI) pada waktu tertentu.

3. Melakukan pengukuran secara berkala dan memperhatikan perkembangan beban agar terhindar dari dampak harminisasi arus ataupun tegangan. 


\section{DAFTAR PUSTAKA}

Arikunto, Suharsimi. (2002). Prosedur Penelitian Suatu Pendekatan Praktek. Jakarta. PT.Rineka Cipta.

Dugan, Roger. (1996). Electrical Power System Quality. New York: Marcell Deker.

Fakultas Teknik (2015). Buku Panduan Penyusunan Skripsi dan Non Skripsi. Jakarta: Fakultas Teknik, Universitas Negeri Jakarta.

Kurniawan, Irfan. (2012). Analisis Pengaruh Harmonisa Terhadap Penyimpangan Pengukuran Energi Listrik Pada KWH Meter Analog Dan Digital. Skripsi Teknik ElektroUniversitas Indonesia.

Pratomo, Eko. (2016). Analisis Kedip Tegangan Akibat Penghasutan Arus Pada Motor Tiga Fasa. Skripsi Teknik Elektro-Universitas Negeri Jakarta.

Sugiarto, Hadi. (2012). Kajian Harmonisa Arus Dan Tegangan Listrik di Gedung Administrasi Politeknik Negeri Pontianak. Jurnal Teknik Elektro, 8: 80-89. 